\title{
In Vitro Study of Adsorption Kinetics of Dextromethorphan Syrup onto Activated Charcoal in Simulated Gastric and Intestinal Fluids
}

\author{
Shobha Regmi, ${ }^{1}$ Balmukunda Regmi, ${ }^{1}$ Sajan Lal Shyaula, ${ }^{2}$ Shiva Pathak, ${ }^{1}$ \\ Bishnu Prasad Bhattarai, ${ }^{1}$ and Saroj Kumar Sah ${ }^{1}$ \\ ${ }^{1}$ Department of Pharmacy, Institute of Medicine, Tribhuvan University, Maharajgunj Medical Campus, Kathmandu, Nepal \\ ${ }^{2}$ Nepal Academy of Science and Technology (NAST), Khumaltar, Lalitpur, Nepal \\ Correspondence should be addressed to Saroj Kumar Sah; sarozsah@iom.edu.np
}

Received 3 October 2016; Revised 15 January 2017; Accepted 8 February 2017; Published 12 March 2017

Academic Editor: Pranav S. Shrivastav

Copyright (c) 2017 Shobha Regmi et al. This is an open access article distributed under the Creative Commons Attribution License, which permits unrestricted use, distribution, and reproduction in any medium, provided the original work is properly cited.

\begin{abstract}
Adsorption kinetics of dextromethorphan (DXM) syrup in simulated gastric and intestinal fluids onto activated charcoal (AC) were investigated in an in vitro model. The adsorption studies were performed as a function of time, initial concentration, and temperature. The quantification of DXM adsorbed onto AC was obtained from the Langmuir adsorption isotherms using HPLC. The maximum adsorption capacities (at 95\% confidence limits) of AC for DXM were 111.615 [106.38; 126.85] mg in simulated intestinal environment ( $\mathrm{pH} 6.8$ ) and 78.314 [86.206; 70.422] $\mathrm{mg}$ in simulated gastric environment ( $\mathrm{pH}$ 1.2). The adsorption capacity of AC for DXM in simulated gastric fluid ( $\mathrm{pH} 1.2)$ was not significantly different from the adoption capacity of AC for DXM in simulated intestinal fluid ( $\mathrm{pH}$ 6.8). Moreover, the adsorption kinetics behavior of dextromethorphan onto AC followed pseudosecond-order kinetics. Our results show that AC in therapeutically acceptable doses can be beneficial in the majority of oral overdose of DXM.
\end{abstract}

\section{Introduction}

In acute oral drug overdose, the drug should be removed as soon as possible, before it is significantly absorbed from the gastrointestinal tract. A nonspecific measure for gastrointestinal decontamination of a poisoned patient is the oral administration of activated charcoal (AC). Oral ingestion of $\mathrm{AC}$ has long been known to be effective in reducing the systemic absorption of many drugs due to its adsorptive properties. Thus, it is taken as a useful agent in the management of acute oral drug overdoses.

Dextromethorphan (DXM) is an antitussive drug. It is one of the active ingredients in many over-the-counter (OTC) cold and cough medicines [1]. Cases of recreational abuse of DXM [2] have been reported in USA, Sweden, Australia, Germany, and Korea, primarily among adolescents and young adults [3]. In a study in the USA during a 2year period from 2004 and 2005, the emergency departments treated over 1,500 children for adverse effects related to OTC cough and cold medication use. A 6-year retrospective study from 1999 to 2004 of the California Poison Control System showed a 10-fold increase in the rate of DXM abuse cases in all ages and a 15-fold increase in the rate DXM abuse cases in adolescents [3]. The risk of overdose, incorrect dosing, and adverse events are increasing in young children due to the greater number of colds they acquire each year [4]. Due to its fashionable color, sweet taste, and careless storage of DXM syrup nearby the access of child population, they seem to be more susceptible toward its overdose. In a study conducted in the USA to monitor trends in DXM abuse by using the National Poison Data System: 2000-2010, the mean annual prevalence of DXM cases reported to poison control centers was 13.4 cases per million population for all ages and 113.0 cases per million for 15-19-year-old people. The prevalence of DXM cases for all ages increased steadily until 2006 to a peak of 17.6 calls/million and subsequently plateaued at 15.7 cases per million in 2010. A preponderance of male adolescents was noted throughout the study period [5]. 
It has been an important impulse for a resurgence of interest in the use of AC in toxicology [6]. The adsorption patterns differ with different drugs. So, there is a need to understand this variability to recognize the proper adsorption patterns of $\mathrm{AC}$ for different drugs in order to calculate the appropriate amount of AC to administer during acute poisoning [7, 8]. In addition, there is a need to study the maximum adsorption capacity of activated charcoal for many drugs and establish a drug-activated charcoal dose relationship to reduce the systemic toxicity of ingested drugs and achieve the maximal efficacy of activated charcoal. Studies on in vitro drug adsorption onto $\mathrm{AC}$ have been carried out at different $\mathrm{pH}$ values to simulate in vivo conditions in the gastrointestinal tract [7-10]. An acidic pH (1.2) has been used to simulate the gastric environment, and basic $\mathrm{pH}$ (6.8) has been used to simulate the environment in the small intestine.

DXM, an OTC drug, is easily available and have a potential of abuse [11]. Although the frequent use of AC in an asymptomatic patient with DXM poisoning has been practiced, data regarding safety and efficacy of AC in the management of DXM poisoning remain largely unknown [12]. Thus, the need of this study was anticipated to investigate in vitro efficacy of activated charcoal in adsorption of DXM. Based on available data from in vivo and in vitro studies, the recommended dose regimen of AC varies between 25 and $100 \mathrm{~g}$ in adults [13], $1 \mathrm{~g} / \mathrm{kg}$ body weight in children [14], or $0.5-$ $2 \mathrm{~g} / \mathrm{kg}$ body weight [15]. For many drugs (or poison as well as pesticides), the adsorption onto AC varies with a change in $\mathrm{pH}$ [16-20]. The main purpose of this study was to elucidate the difference in maximum adsorption capacity of DXM onto activated charcoal in simulated in vitro environments at two extremities of $\mathrm{pH}$ inside gastrointestinal tract. It is well known that oral AC should not only adsorb toxic compounds effectively, but also adsorb the particular intoxicants as fast as possible. This leads to the statement that the investigations on the kinetics of adsorption of different drugs are still under exploration [21]. In our study, we have investigated the in vitro adsorption of DXM at two different $\mathrm{pH}$ values $(\mathrm{pH} 1.2$ and $\mathrm{pH}$ 6.8) of simulated gastric and intestinal fluids onto AC and elucidated the kinetics of the adsorption.

\section{Material and Methods}

2.1. Chemicals and Reagents. Standard dextromethorphan was obtained from Lomus pharmaceuticals private limited, Gothatar, Bhaktapur, Nepal. Clinical grade activated charcoal powder (D-Tox powder; Asian Pharmaceuticals Pvt. Ltd, Nepal) was purchased from a community pharmacy. All the reagents such as potassium dihydrogen phosphate $\left(\mathrm{KH}_{2} \mathrm{PO}_{4}\right)$, sodium hydroxide $(\mathrm{NaOH})$, and orthophosphoric acid were of analytical grade. Methanol and water of HPLC grade were used in the preparation of the mobile phase for HPLC. The simulated gastric and intestinal fluid environments ( $\mathrm{pH} 1.2$ and $\mathrm{pH}$ 6.8) were prepared as per United States Pharmacopoeia, 2002 [22]. Simulated gastric fluid $\mathrm{pH}$ 1.2 (SGF) was prepared by taking $2 \mathrm{~g} \mathrm{NaCl}$ and $7 \mathrm{~mL}$ concentrated $\mathrm{HCl}$ in $1000 \mathrm{~mL}$ distilled water. Simulated intestinal fluid, $\mathrm{pH} 6.8$, was prepared by taking $68.05 \mathrm{~g}$ potassium dihydrogen phosphate $\left(\mathrm{KH}_{2} \mathrm{PO}_{4}\right)$ and $8.96 \mathrm{~g}$ sodium hydroxide
$(\mathrm{NaOH})$ in $10 \mathrm{~L}$ water. Similarly, 0.1 M phosphate buffer of $\mathrm{pH} 3$ for mobile phase was prepared according to European pharmacopoeia; $13.6 \mathrm{~g}$ of potassium dihydrogen phosphate was dissolved in $900 \mathrm{~mL}$ of water, $\mathrm{pH}$ being adjusted to 3.0 with phosphoric acid, and diluted to $1000 \mathrm{~mL}$.

2.2. Calibration Curves. DXM stock solution of $1000 \mu \mathrm{g} / \mathrm{mL}$ was prepared in simulated gastric and intestinal fluids. Then, different concentrations of standard solutions of DXM were obtained by dilution. The desired concentrations were $500 \mu \mathrm{g} / \mathrm{mL}, 250 \mu \mathrm{g} / \mathrm{mL}, 125 \mu \mathrm{g} / \mathrm{mL}, 62.5 \mu \mathrm{g} / \mathrm{mL}, 31.25 \mu \mathrm{g} / \mathrm{mL}$, and $15.625 \mu \mathrm{g} / \mathrm{mL}$. Each concentration was filtered with the $0.45 \mu \mathrm{m}$ filter and injected in HPLC. The separation was achieved by C18 column using an isocratic mobile phase consisting of methanol-dihydrogen phosphate buffer at $\mathrm{pH}$ $3(50: 50, \% \mathrm{v} / \mathrm{v})$. The analysis was performed at a flow rate of $1 \mathrm{~mL} / \mathrm{min}$ and at a detection wavelength of $220 \mathrm{~nm}$. The analysis was performed at oven temperature $32^{\circ} \mathrm{C}$. Prior to any analysis, the mobile phase was degassed and filtered using $0.45 \mu \mathrm{m}$ filters. The system was equilibrated with the mobile phase before injection. The area obtained was then plotted against the known concentration and calibration curve was obtained [23].

2.3. Adsorption Study. To obtain Langmuir's adsorption isotherm, AC and dextromethorphan (DXM syrup $10 \mathrm{mg} /$ $\mathrm{mL}$ ) were mixed in different proportions of $1: 1,3: 1,6: 1$, and $15: 1$ in $50 \mathrm{~mL}$ volumetric flasks. The amount of dextromethorphan in all the experiments was $30 \mathrm{mg}$. The sample mixtures in simulated gastric and intestinal fluids were bathsonicated for $15 \mathrm{~min}$ at $37^{\circ} \mathrm{C}$. The solution was filtered through a filter paper. Experiments were performed in triplicate. The filtrate was then analyzed by HPLC. Before injecting the sample into HPLC, it was refiltered through $0.45 \mu \mathrm{m}$ filter paper. The separation was achieved on LC18 column using a mobile phase constituting $50: 50(\% \mathrm{v} / \mathrm{v})$ mixture of methanol and water. The analysis was performed at a flow rate of $1 \mathrm{~mL} / \mathrm{min}$ [23].

2.4. Kinetics Study. In order to perform kinetics study of the drug adsorption over the AC, the suspension of DXM and the AC at ratios varying from $1: 1$ up to $1: 12$ was kept in 6 different flasks and mixed. Each flask was taken out of the sonicator in $5,10,15,20,25$, and $30 \mathrm{~min}$. After filtration, solutions were analyzed by the method as described previously. The data obtained were examined with pseudo-first-order and pseudo-second-order reaction equations [24]. The kinetics study of drug adsorption was performed in both simulated gastric and intestinal fluids.

2.5. DXM Analysis. The concentrations of DXM, before and after the attainment of equilibrium during adsorption phenomenon, were estimated using HPLC. The data obtained using HPLC were plotted on the calibration curve to obtain the exact amount of DXM adsorbed in the simulated gastrointestinal environments.

2.6. Estimation of the Langmuir Parameter. A derived equation of the Langmuir adsorption isotherm was used to 
estimate $q_{m}$ (monolayer capacity) that reflects the maximal quantity of the drugs (in mg) adsorbed per gram AC. The $q_{m}$ was calculated from the following equation.

$$
\frac{C_{e}}{q_{e}}=\frac{1}{q_{m} K}+\frac{C_{e}}{q_{m}}
$$

where $C_{e}(\mathrm{mg} / \mathrm{L})$ is the drug concentration in the liquid phase at equilibrium and " $K$ " is Langmuir constant. $q_{e}$ is equilibrium adsorbed quantity ( $\mathrm{mg}$ of adsorbate per gram of adsorbent) calculated as $q_{e}=V\left(C_{0}-C_{e}\right) / W$, where " $V$ " is total volume in litre and $W$ is the quantity of $\mathrm{AC}$ in grams; $C_{0}$ $(\mathrm{mg} / \mathrm{L})$ is the initial quantity of dextromethorphan and $C_{e}$ is the concentration after the adsorption.

The Langmuir isotherm adsorption parameter " $q_{m}$ " was obtained by linear least square fitting of the experimental data. A plot of $C_{e} / q_{e}$ versus $C_{e}$ yields a straight line with the slope $1 / q_{m}$ and intercept $1 / q_{m} K$.

2.7. Calculation of Adsorption Energy. Langmuir constant " $K$ " calculated from the Langmuir equation can be related to the adsorption free energy, by the following equation: $G=\mathrm{RT} \ln K$, where " $R$ " is the universal gas constant (1.987 $\mathrm{cal} \mathrm{mol}^{-1} \mathrm{~K}^{-1}$ ) and " $T$ " is the absolute temperature (Kelvin) taken as $303 \mathrm{~K}$. Free energy is a measure of the capacity of the system to do work. If the value is negative, the system will have a tendency to do work spontaneously (exothermic reaction). Free energy is measured in kilojoules per mole, also called Gibb's free energy. The negative values of free energy change show that the solute is more concentrated on the adsorbent than in the bulk solution; that is, the system has reached equilibrium [25].

2.8. Calculation of Suitability of Adsorbent to Adsorbatel Constant Separation Factor. To determine the characteristic behavior of the adsorption, constant separation factor $(R)$ was used. The equation is given as; $R=1 /\left(1+K X_{0}\right)$, where $X_{0}$ is the initial amount of the adsorbate. " $R$ " is a direct function of " $K$ " and is related to the slope $1 / q_{m}$ of the linearized Langmuir expression. The slope of the linearized Langmuir isotherm can be used to interpret the type of adsorption by using the value of " $R$ " as follows: $R>1.0$, not suitable; $R=1.0$, linear; $0<R<1.0$ suitable (good adsorbent); and $R=0$, irreversible.

2.9. Statistical Analysis. Data analysis was conducted by the Microsoft excel 2010 and IBM SPSS Statistics for Windows, Version 20.0 (Armonk, NY: IBM Corp.). Statistical values were calculated using unpaired $t$-tests. Differences with $p$ values of less than 0.05 were considered statistically significant.

\section{Results}

3.1. Adsorption Saturation of AC with Dextromethorphan. The final concentration of DXM $\left(C_{e} ; \mathrm{mg} / \mathrm{L}\right)$ was plotted against the amount of DXM adsorbed per gram of charcoal $q_{e}(\mathrm{mg} / \mathrm{g}$ of $\mathrm{AC})$ for each sample in both SGF and SIF. Plots are as shown in Figure 1.
TABLE 1: Maximal adsorption capacity, $q_{m}$ (mg DXM adsorbed/g of AC) in SGF and SIF.

\begin{tabular}{lc}
\hline Simulated fluid & $q_{m}$ (mg of DXM adsorbed/g of AC) \\
\hline $\begin{array}{l}\text { Simulated gastric fluid } \\
\text { (pH 1.2) }\end{array}$ & $78.314[86.206 ; 70.422]$ \\
$\begin{array}{l}\text { Simulated intestinal fluid } \\
(\mathrm{pH} \mathrm{6.8})\end{array}$ & $116.615[106.38 ; 126.85]$ \\
\hline
\end{tabular}

TABLE 2: Effect of $\mathrm{pH}$ of simulated gastrointestinal fluids on MAC. This shows that there is no significant effect of $\mathrm{pH}$ in the MAC.

\begin{tabular}{lcc}
\hline & & $p$ value \\
\hline $\mathrm{pH} 6.8$ & $\mathrm{pH} 1.2$ & 0.097 \\
\hline
\end{tabular}

3.2. Maximal Adsorption of DXM from Simulated Gastrointestinal Fluids. Langmuir adsorption isotherm was used to calculate the maximal adsorption capacity $\left(q_{m}\right)$ (mg DXM adsorbed/g of $\mathrm{AC}$ ). The maximum adsorption capacities (MAC) of AC for DXM in SGF and SIF were different. Each gram of AC adsorbed $111.615 \mathrm{mg}$ [106.38; 126.85] DXM at intestinal $\mathrm{pH}$ and 78.314 [86.206; 70.422] mg DXM at gastric environment. In other words, AC at its standard dose of $50 \mathrm{~g}$ can eliminate $5.8307 \mathrm{~g}$ [5319-6342.5] DXM at the intestinal environment and 3.9157 $\mathrm{g}$ [4310.3-3521.1 g] DXM at gastric environment (Table 1).

3.3. Effect of $p H$ of Simulated Gastrointestinal Fluids on Maximum Adsorption Capacity of AC. There was no significant effect of $\mathrm{pH}$ of simulated gastrointestinal fluids in the MAC (Table 2). The significant difference was measured at $95 \%$ confidence interval (CI) using independent sample $t$-test and was considered significant if $p \leq 0.05^{*}$.

3.4. Equilibrium Isotherm Model for Adsorption of DXM onto $A C$. Equilibrium isotherm equations were used to describe the experimental adsorption data. The two most common isotherms for describing solid-liquid adsorption systems are Langmuir and Freundlich adsorption isotherms. Langmuir's plots showed the excellent coefficient of determination $\left(R^{2}\right)$ at both pHs (1.2 and 6.8) for simulated fluid, indicating the excellent fitting model to the experiment data (Figures 2 and 3).

3.5. Comparison of Linear Coefficient of Determination, $R^{2}$, for Different Adsorption Isotherm Model. The data were fitted on both Langmuir and Freundlich adsorption isotherms (Table 3). The Langmuir isotherm plot showed the excellent coefficient of determination compared with that of Freundlich isotherm for each trial of study. Thus, results were analyzed by plotting the data on Langmuir isotherm equation.

3.6. Calculation of Adsorption Energy $(G=\mathrm{RT} \ln K)$ and Suitability of Adsorbent to Adsorbate/Constant Separation Factor $\left(R=1 /\left(1+K X_{0}\right)\right)$. The negative values of change in Gibb's free energy indicated that the solute was more concentrated on the adsorbent rather than in the bulk solution, and equilibrium condition was attained (Table 4). 


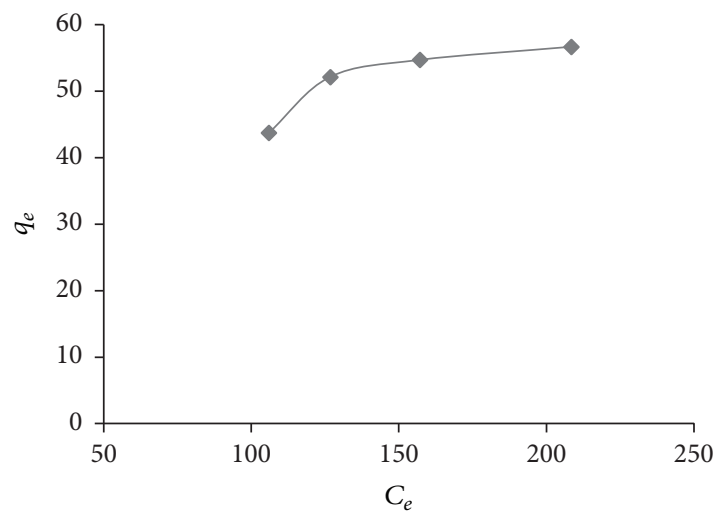

Adsorption saturation curve of $\mathrm{AC}$ with dextromethorphan in simulated gastric fluid

(a)

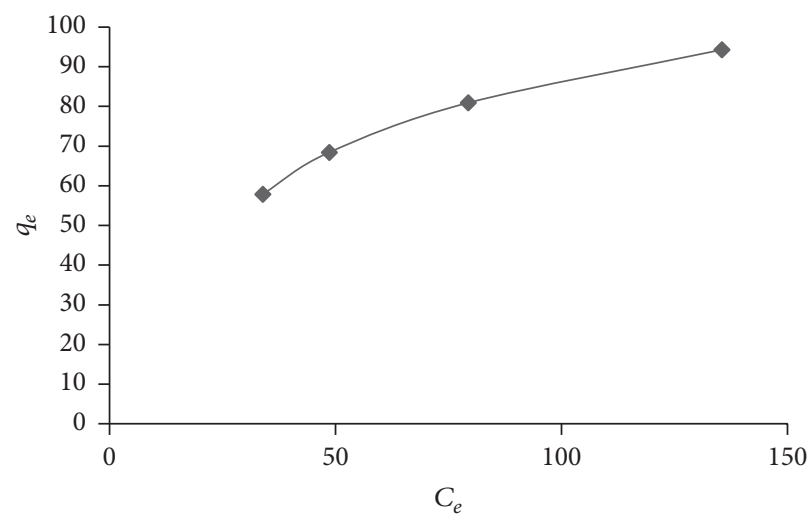

Adsorption saturation curve of $\mathrm{AC}$ with dextromethorphan in simulated intestinal fluid

(b)

FIGURE 1: Adsorption saturation curve of AC with DXM in (a) simulated gastric fluid and (b) simulated intestinal fluid.

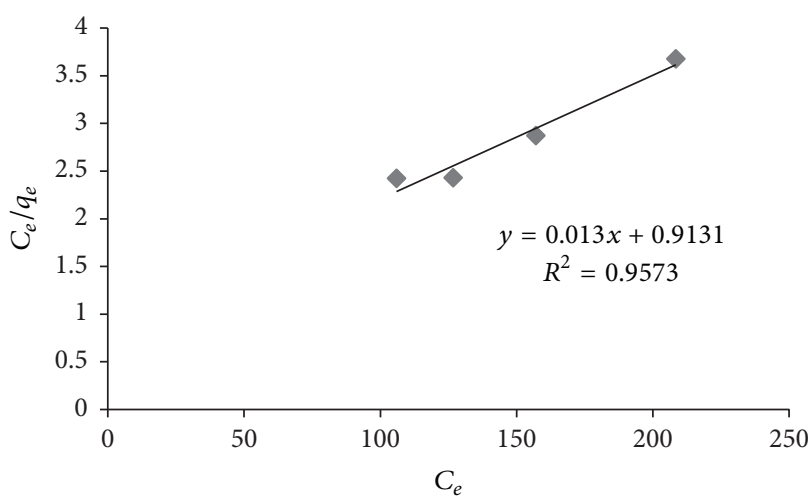

Langmuir plot for dextromethorphan adsorption onto $\mathrm{AC}$ in simulated gastric fluid

(a)

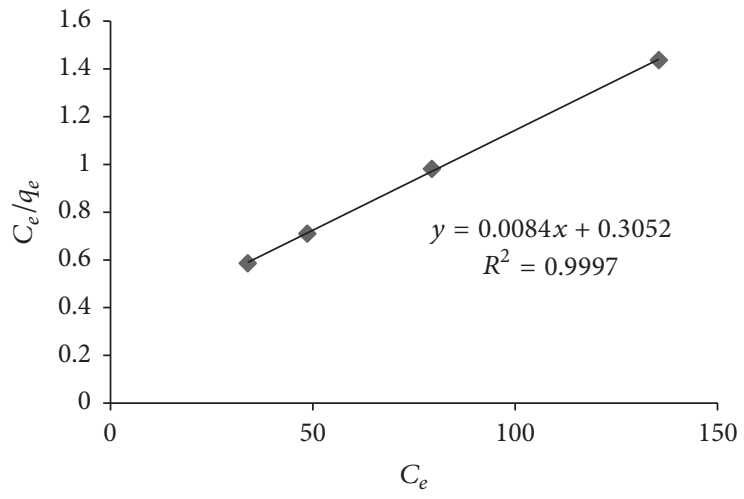

Langmuir plot for dextromethorphan adsorption onto AC in simulated intestinal fluid

(b)

FIGURE 2: Langmuir plot of AC with DXM in (a) simulated gastric fluid and (b) simulated intestinal fluid.

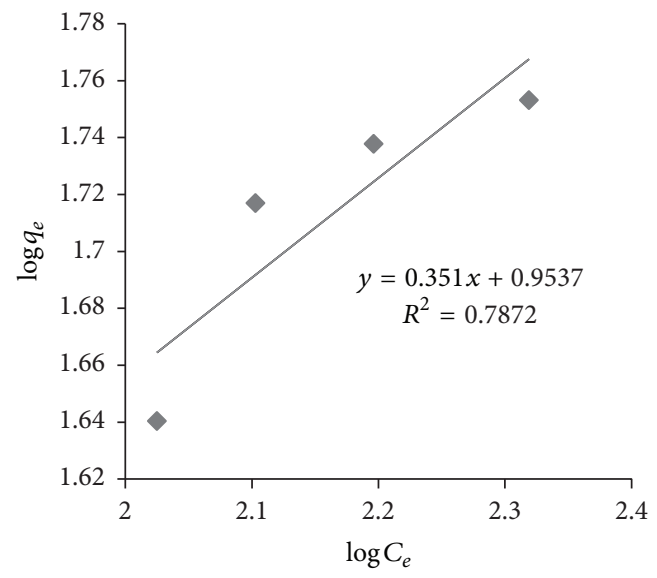

Freundlich plot for dextromethorphan adsorption onto AC in simulated gastric fluid

(a)

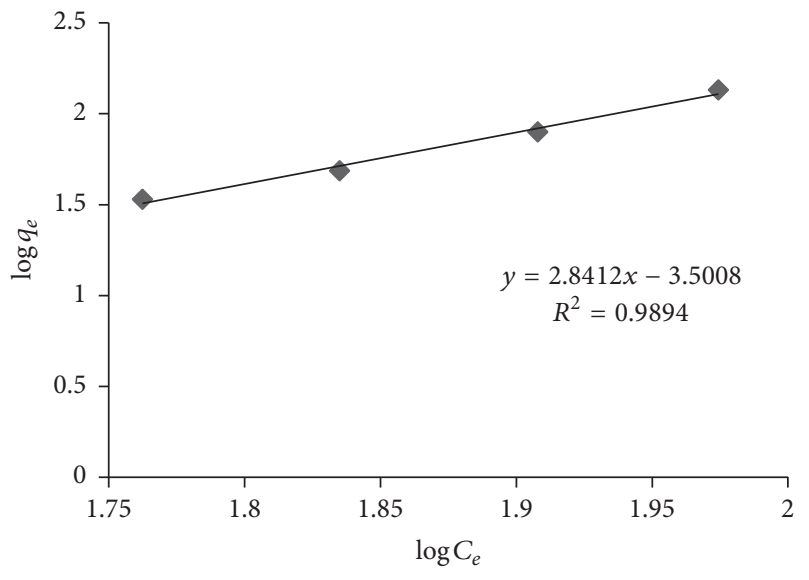

Freundlich plot for dextromethorphan adsorption onto AC in simulated intestinal fluid

(b)

FIgURE 3: Freundlich plot of AC with DXM in (a) simulated gastric fluid and (b) simulated intestinal fluid. 
TABLE 3: Comparison of coefficient of determination, $R^{2}$.

\begin{tabular}{lcc}
\hline Adsorption isotherm & $R^{2}$ & $R^{2}$ \\
& SGF & SIF \\
\hline Langmuir isotherm & 0.9573 & 0.9997 \\
Freundlich isotherm & 0.7872 & 0.9894 \\
\hline
\end{tabular}

TABLE 4: Calculation of adsorption energy $(G=\mathrm{RT} \ln K)$.

\begin{tabular}{lcccc}
\hline$K$ & $\begin{array}{l}G(\mathrm{pH} 1.2) \\
\text { Kcal/mole }\end{array}$ & $K$ & $\begin{array}{l}G(\mathrm{pH} \mathrm{6.8)} \\
\text { Kcal/mole }\end{array}$ & Inference \\
\hline 0.01498 & -2.5286 & 0.03185 & -2.075 & Positive \\
\hline
\end{tabular}

TABLE 5: Calculation of suitability of adsorbent to adsorbate/constant separation factor/suitability of adsorption $\left(R=1 /\left(1+K X_{0}\right)\right)$.

\begin{tabular}{lccc}
\hline$R(\mathrm{pH} 1.2)$ & Inference & $R(\mathrm{pH} \mathrm{6.8)}$ & Inference \\
\hline 0.672 & Suitable & 0.327 & Suitable \\
\hline
\end{tabular}

TABLE 6: Comparison of coefficient of determination, $R^{2}$.

\begin{tabular}{lcccc}
\hline $\begin{array}{l}\text { Adsorption } \\
\text { kinetics }\end{array}$ & $\begin{array}{c}R^{2} \\
\text { SGF }\end{array}$ & $\begin{array}{c}R^{2} \\
\text { SIF }\end{array}$ & $\begin{array}{c}K_{2} \\
\text { SGF }\end{array}$ & $\begin{array}{c}K_{2} \\
\text { SIF }\end{array}$ \\
\hline $\begin{array}{l}\text { Pseudo-first- } \\
\text { order }\end{array}$ & 0.437 & 0.6599 & & \\
$\begin{array}{l}\text { Pseudo-second- } \\
\text { order }\end{array}$ & 0.9968 & 1.000 & 0.02433 & 0.0809 \\
\hline
\end{tabular}

The value of constant separation factor " $R$ " is less than 1 in all of the above cases. This showed that AC is a good adsorbent for DXM (Table 5).

3.7. Adsorption Kinetics Study. Kinetic studies for the adsorption of DXM onto AC were studied and data were plotted to two most used kinetic model equations; pseudo-firstorder and pseudo-second-order model. Results showed that the adsorption kinetics behavior of DXM onto AC followed pseudo-second-order kinetics model rather than pseudofirst-order kinetics. For pseudo-first-order kinetics, the plot of $\log \left(q_{e}-q_{t}\right)$ versus " $t$ " should be a straight line with negative slope. When we plotted this value, we obtained a line with negative slope but $R^{2}$ value was less than that of the pseudo-second-order plot. When we plotted a graph for $t / q_{t}$ versus " $t$ " according to pseudo-second-order model, we obtained a straight line with positive slope and good $R^{2}$ value (>0.9968). So, the adsorption studies of DXM on AC followed the pseudo-second-order kinetic model. This is represented in Figures 4 and 5.

3.8. Comparison of $R^{2}$ for Different Adsorption Kinetic Models. The data were plotted on both pseudo-first- and pseudosecond-order equation. The pseudo-second-order model yielded an excellent coefficient of determination for each trial of study compared to that of pseudo-first-order (Table 6). Thus, all the results were analyzed by fitting the data on pseudo-second-order equation.

\section{Discussion}

The adsorption studies were performed in simulated environments of pH 1.2 and 6.8 to mimic the human gastrointestinal tract. To achieve the saturation of AC with study drug, the proportion of the mass of AC:DXM was varied from $1: 1$ to $15: 1$. DXM in liquid form from the cough syrup was taken in order to simulate in vivo intoxication conditions when patients are intoxicated with the DXM syrup available in the market.

Equilibrium isotherms were used to describe the experimental adsorption data. The data were plotted onto the two most common adsorption isotherms; Langmuir isotherm and Freundlich isotherm, and their coefficient of determination $\left(R^{2}\right)$ was compared to get the best adsorption isotherm equation. Based on the value of $R^{2}$, Langmuir isotherm was selected. To fit the data into the Langmuir adsorption isotherm, the value $R^{2}$ should be $0.87-1$, indicating that the experimental data fits strongly into the individual regression. In the current study, all the $R^{2}$ values satisfied this condition and greater values of $R^{2}$ were found in Langmuir adsorption isotherm (0.9573 at simulated gastric fluid and 0.9997 in simulated intestinal fluid, resp.). Although Freundlich isotherm also fitted in SIF, a better value of $R^{2}$ was obtained with Langmuir isotherm. The study showed the suitability of Langmuir adsorption isotherm. The $R^{2}$ value in the current study was higher in simulated intestinal fluid compared with that in simulated gastric fluid. This can be explained on the basis of the excellent logarithmic relationship observed between adsorption affinity and solubility of DXM in simulated intestinal fluid.

Adsorption kinetics models were used to describe the experimental data of adsorption of DXM. The data were plotted onto two common adsorption kinetics models; pseudofirst-order and pseudo-second-order model, and their coefficients of determination $\left(R^{2}\right)$ were compared. The pseudosecond-order model showed the best results in both SGF and SIF. To fit the data, the $R^{2}$ value should range from 0.87 to 1.00 . The pseudo-second-order kinetics model fitted for this study with good $R^{2}(>0.9961)$ value, both in gastric and intestinal $\mathrm{pH}$. The adsorption rate was higher in SIF than SGF.

The difference in maximum adsorption capacity of AC for DXM in SGF and SIF was insignificant $(p=0.097)$. $\mathrm{AC}(50 \mathrm{~g})$ adsorbed $5.319 \mathrm{~g}$ to $6.3425 \mathrm{~g}$ of DXM (mean value: $5.8307 \mathrm{~g}$; i.e., 19 bottles of $100 \mathrm{~mL}$ capacity in which each $5 \mathrm{~mL}$ contains $15 \mathrm{mg}$ of DXM) at intestinal environment and $4.3103 \mathrm{~g}$ to $3.5211 \mathrm{~g}$ (mean value: $3.9157 \mathrm{~g}$; i.e., 13 bottles of $100 \mathrm{~mL}$ capacity in which each $5 \mathrm{~mL}$ contains $15 \mathrm{mg}$ of DXM) at gastric environment.

The calculation of Gibb's free energy and calculation of suitability of adsorption factor showed that the reaction was spontaneous, and equilibrium was reached. Thus, these data indicated that charcoal is suitable for adsorption of this drug [25]. A study performed by American Association of Poison Control Centers has concluded that activated charcoal could be administered as part of the management of a DXM poisoned patient despite the lack of specific data to support its use [12]. In the current study, the DXM showed 


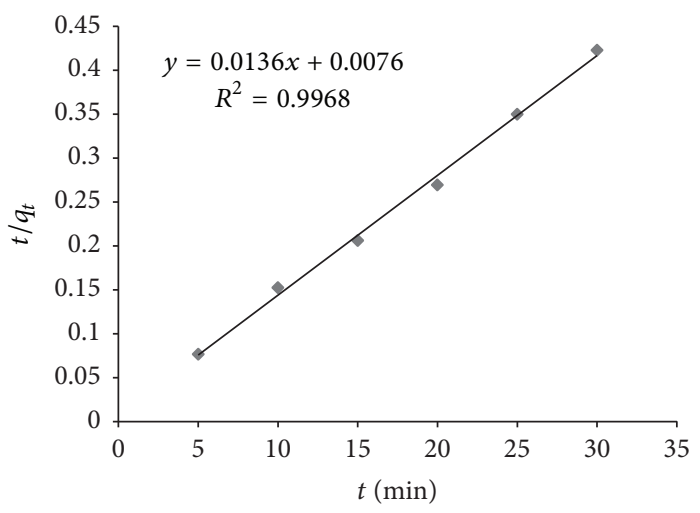

Pseudo-second-order plot for dextromethorphan adsorption onto AC in simulated gastric fluid

(a)

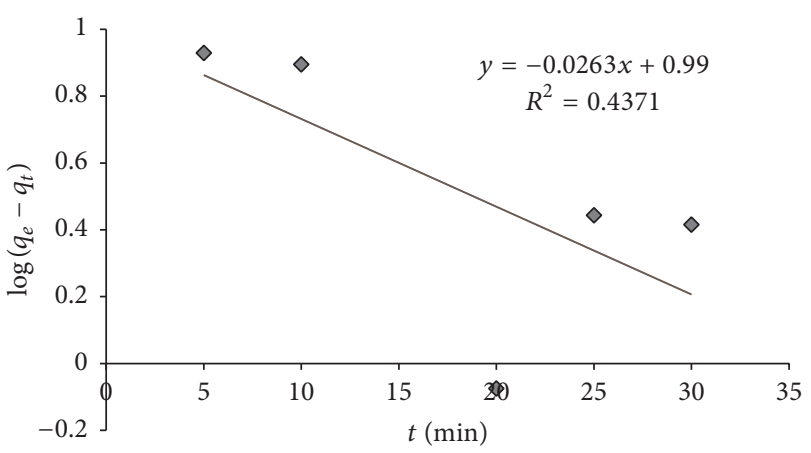

Pseudo-first-order plot for dextromethorphan adsorption onto AC in simulated gastric fluid

(b)

FIGURE 4: (a) Pseudo-second-order plot for adsorption of DXM on AC in SGF and (b) pseudo-first-order plot for adsorption of DXM on AC in SGF.

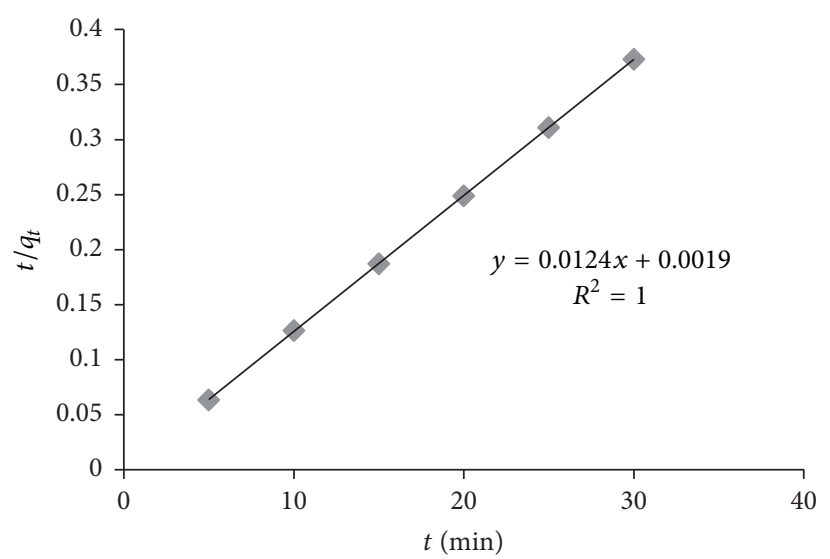

Pseudo-second-order plot for dextromethorphan adsorption onto AC in simulated intestinal fluid

(a)

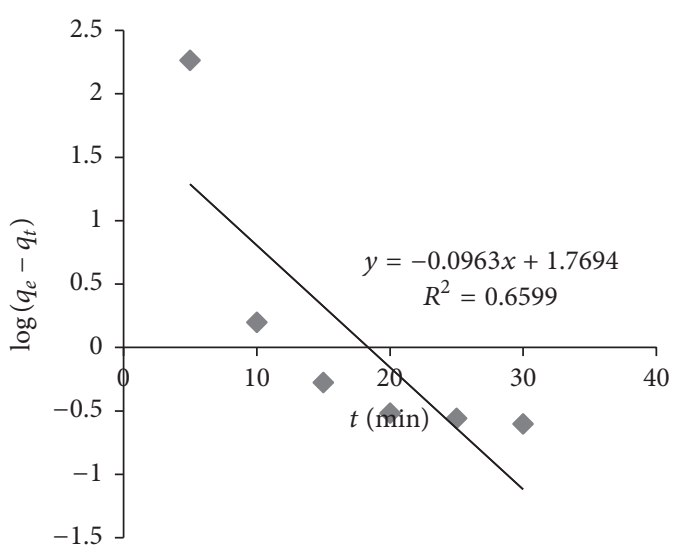

Pseudo-first-order plot for dextromethorphan adsorption onto AC in simulated intestinal fluid

(b)

FIGURE 5: (a) Pseudo-second-order plot for adsorption of DXM on AC in SIF and (b) pseudo-first-order plot for adsorption of DXM on AC in SIF.

good adsorption; $78.314 \mathrm{mg} / \mathrm{g}$ of charcoal was adsorbed in simulated gastric fluid and $116.615 \mathrm{mg} / \mathrm{g}$ of charcoal was adsorbed in simulated intestinal fluid $(p=0.097)$. Our results further support the use of activated charcoal for DXM poisoning in clinical settings.

\section{Conclusion}

The main objective of our research was to investigate the adsorption capacity of activated charcoal for DXM syrup. Further studies need to be conducted to correlate our in vitro data with the in vivo conditions. Nonetheless, the present in vitro study shows that AC can adsorb sufficient amount of DXM. This in vitro study showed that sufficient amount of DXM can be adsorbed by the activated charcoal in its standard treatment dose. The use of charcoal might be the most effective therapeutic approach for DXM poisoning.

\section{Competing Interests}

The authors declare that they have no competing interests.

\section{References}

[1] P. Amaratunga, M. Clothier, B. L. Lemberg, and D. Lemberg, "Determination of dextromethorphan in oral fluid by LC-MSMS," Journal of Analytical Toxicology, vol. 40, no. 5, pp. 360-366, 2016.

[2] P. J. Perry, K. Fredriksen, S. Chew et al., "The effects of dextromethorphan on driving performance and the standardized 
field sobriety test," Journal of Forensic Sciences, vol. 60, no. 5, pp. 1258-1262, 2015

[3] T. Tartu and E. M. L. De Lima, "WHO Expert Committee on Drug Dependence".

[4] T. Ryan, M. Brewer, and L. Small, "Over-the-counter cough and cold medication use in young children," Pediatric Nursing, vol. 34, no. 2, pp. 174-184, 2008.

[5] M. D. Wilson, R. W. Ferguson, M. E. Mazer, and T. L. Litovitz, "Monitoring trends in dextromethorphan abuse using the National Poison Data System: 2000-2010," Clinical Toxicology, vol. 49, no. 5, pp. 409-415, 2011.

[6] C. M. A. Rademaker, A. van Dijk, M. H. de Vries, F. Kadir, and J. H. Glerum, "A ready-to-use activated charcoal mixture: adsorption studiesin vitro and in dogs: its influence on the intestinal secretion of theophylline in a rat model," Pharmaceutisch Weekblad Scientific Edition, vol. 11, no. 2, pp. 56-60, 1989.

[7] S. Panthee and S. P. Lohani, "In vitro adsorption studies of paracetamol to activated charcoal capsule, powder and suspension," The Open Toxicology Journal, vol. 2, no. 1, pp. 22-25, 2008.

[8] L. C. G. Hoegberg, H. R. Angelo, A. B. Christophersen, and H. R. Christensen, "Effect of ethanol and $\mathrm{pH}$ on the adsorption of acetaminophen (paracetamol) to high surface activated charcoal, in vitro studies," Journal of Toxicology: Clinical Toxicology, vol. 40, no. 1, pp. 59-67, 2002.

[9] D. N. Bailey and J. R. Briggs, "The effect of ethanol and $\mathrm{pH}$ on the adsorption of drugs from simulated gastric fluid onto activated charcoal," Therapeutic Drug Monitoring, vol. 25, no. 3, pp. 310-313, 2003.

[10] J. M. Valente Nabais, B. Ledesma, and C. Laginhas, "Removal of amitriptyline from simulated gastric and intestinal fluids using activated carbons," Journal of Pharmaceutical Sciences, vol. 100, no. 12, pp. 5096-5099, 2011.

[11] M.-Y. Lo, M. W. Ong, J.-G. Lin, and W.-Z. Sun, "Codeine consumption from over-the-counter anti-cough syrup in Taiwan: a useful indicator for opioid abuse," Acta Anaesthesiologica Taiwanica, vol. 53, no. 4, pp. 135-138, 2015.

[12] P. A. Chyka, A. R. Erdman, A. S. Manoguerra et al., "Dextromethorphan poisoning: an evidence-based consensus guideline for out-of-hospital management," Clinical Toxicology, vol. 45, no. 6, pp. 662-677, 2007.

[13] D. Cooney, Activated Charcoal in Medical Applications, Marcel Dekker, New York, NY, USA, 2nd edition, 1995.

[14] P. A. Chyka and D. Seger, "Position statement: single-dose activated charcoal," Journal of Toxicology - Clinical Toxicology, vol. 35, no. 7, pp. 721-741, 1997.

[15] M. Smilkstein, "Techniques used to prevent gastrointestinal absorption of toxic compounds," in Goldfrank's Toxicologic Emergencies, pp. 35-51, Appleton \& Lange, Stamford, Conn, USA, 6th edition, 1998.

[16] C. A. Bainbridge, E. L. Kelly, and W. D. Walkling, "In vitro adsorption of acetaminophen onto activated charcoal," Journal of Pharmaceutical Sciences, vol. 66, no. 4, pp. 480-483, 1977.

[17] P. J. Neuvonen, K. T. Olkkola, and T. Alanen, "Effect of ethanol and $\mathrm{pH}$ on the adsorption of drugs to activated charcoal: Studies In Vitro And In Man," Acta Pharmacologica et Toxicologica, vol. 54, no. 1, pp. 1-7, 1984.

[18] E. M. Sellers, V. Khouw, and L. Dolman, "Comparative drug adsorption by activated charcoal," Journal of Pharmaceutical Sciences, vol. 66, no. 11, pp. 1640-1641, 1977.
[19] A. T. Sitoura, J. Atta-Politou, and M. A. Koupparis, "In vitro adsorption study of fluoxetine onto activated charcoal at gastric and intestinal $\mathrm{pH}$ using high performance liquid chromatography with fluorescence detector," Journal of Toxicology - Clinical Toxicology, vol. 35, no. 3, pp. 269-276, 1997.

[20] H. Guven, Y. Tuncok, S. Gidener et al., "in vitro adsorption of dichlorvos and parathion by activated charcoal," Journal of Toxicology: Clinical Toxicology, vol. 32, no. 2, pp. 157-163, 1994.

[21] A. P. Terzyk and G. Rychlicki, “The influence of activated carbon surface chemical composition on the adsorption of acetaminophen (paracetamol) in vitro: the temperature dependence of adsorption at the neutral pH," Colloids and Surfaces A: Physicochemical and Engineering Aspects, vol. 163, no. 2-3, pp. 135-150, 2000.

[22] J. Pharmacopoeia, “United States' Pharmacopeia," 2002.

[23] M. R. Louhaichi, S. Jebali, M. H. Loueslati, N. Adhoum, and L. Monser, "Simultaneous determination of pseudoephdrine, pheniramine, guaifenisin, pyrilamine, chlorpheniramine and dextromethorphan in cough and cold medicines by high performance liquid chromatography," Talanta, vol. 78, no. 3, pp. 991997, 2009.

[24] E. K. Putra, R. Pranowo, J. Sunarso, N. Indraswati, and S. Ismadji, "Performance of activated carbon and bentonite for adsorption of amoxicillin from wastewater: mechanisms, isotherms and kinetics," Water Research, vol. 43, no. 9, pp. 24192430, 2009.

[25] A. M. Aljeboree, A. N. Alshirifi, and A. F. Alkaim, "Kinetics and equilibrium study for the adsorption of textile dyes on coconut shell activated carbon," Arabian Journal of Chemistry, 2014. 

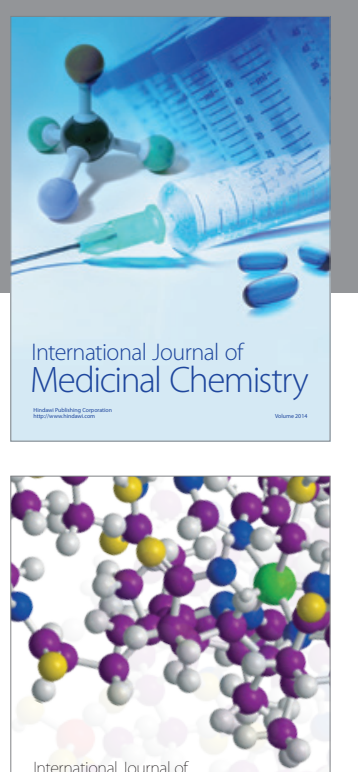

Carbohydrate Chemistry

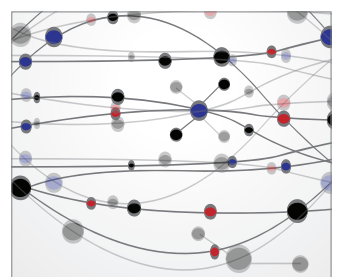

The Scientific World Journal
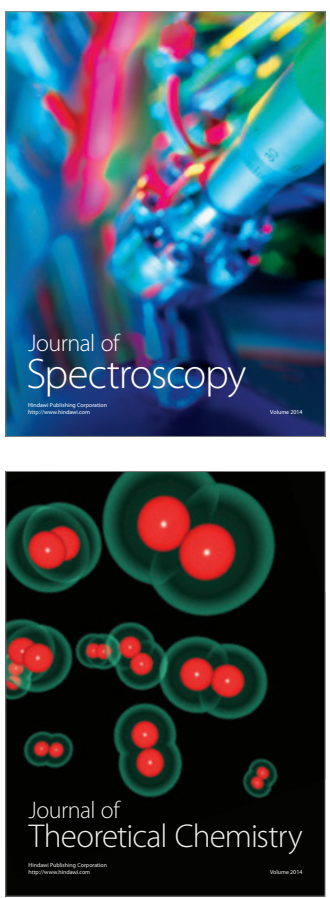
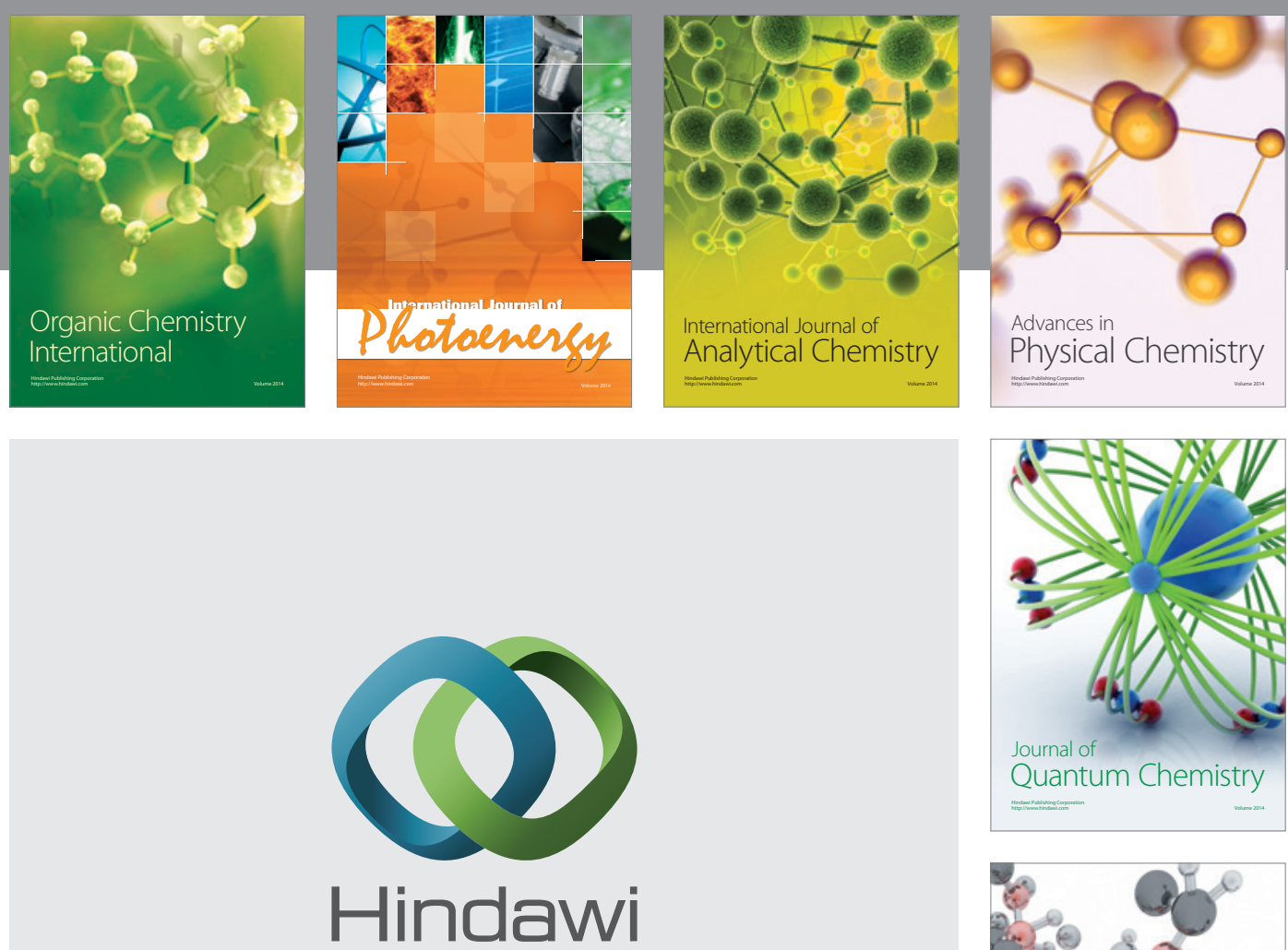

Submit your manuscripts at

https://www.hindawi.com

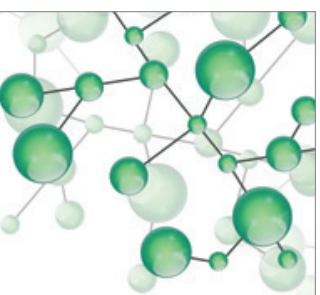

International Journal of

Inorganic Chemistry
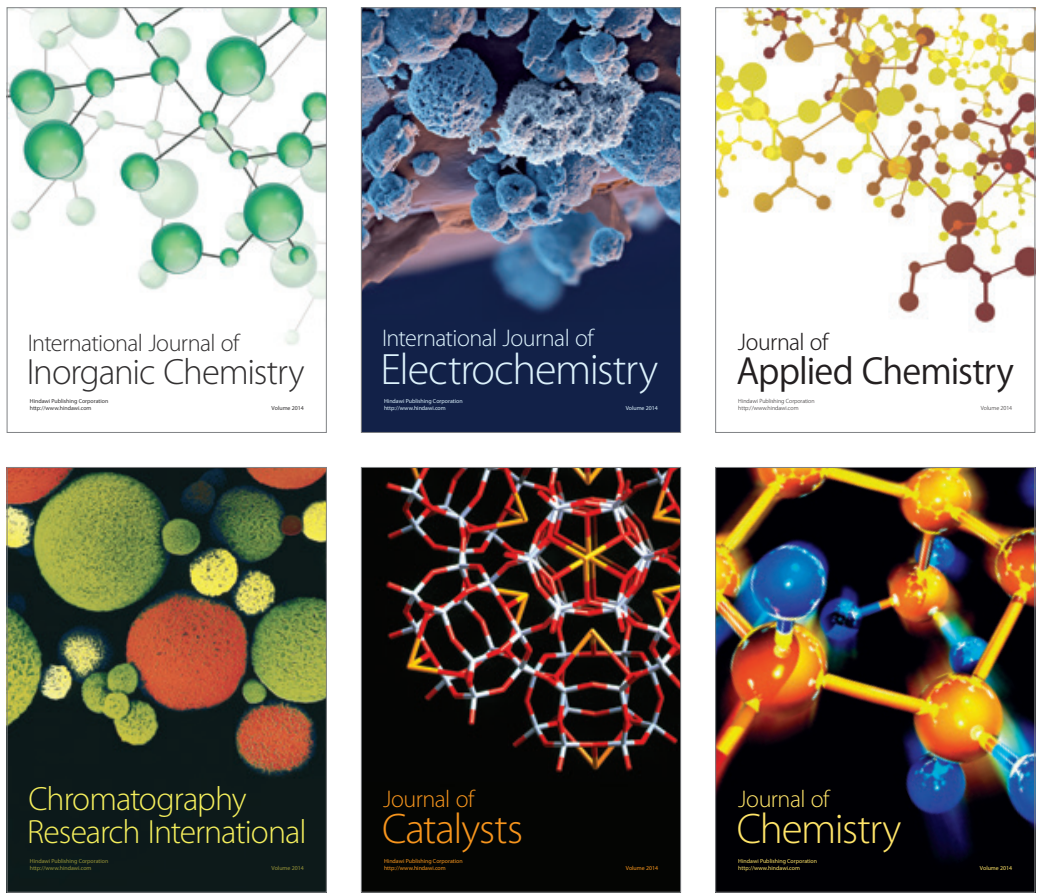

Journal of

Applied Chemistry
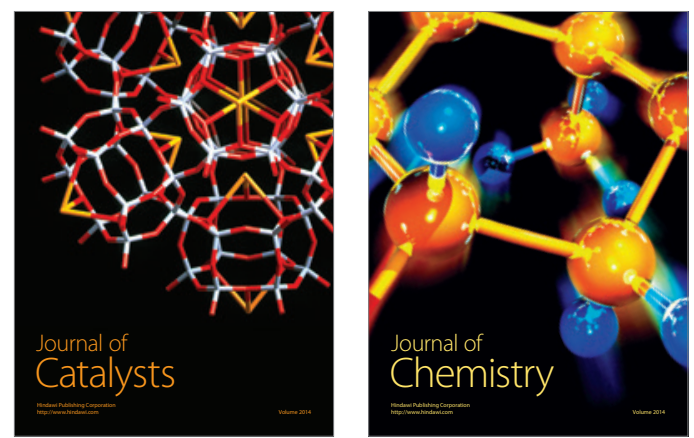
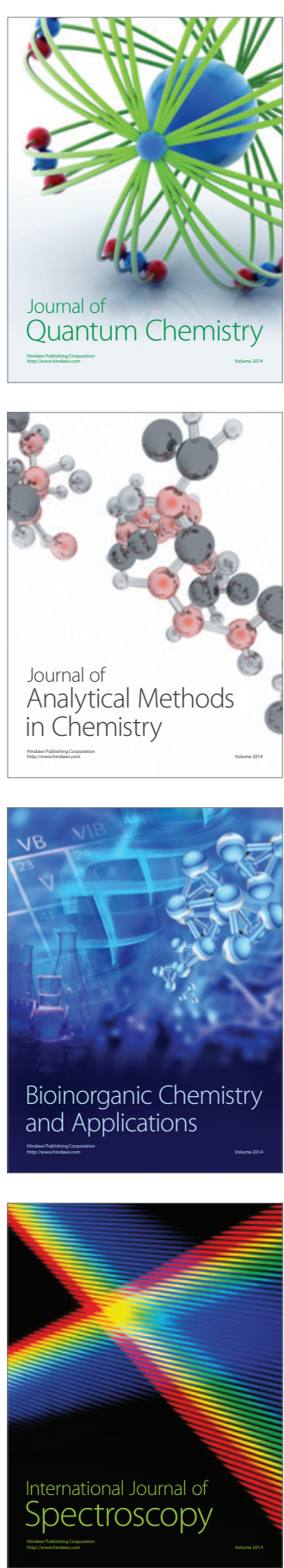